\title{
Hitting the Mark: Learners' Perceptions of Course Design in a Foundation ESOL Program
}

\author{
Malcolm N. MacDonald, Richard Badger, \\ and Goodith White
}

This article investigates a first-year undergraduate program in TESOL consisting of three strands: a language-based course, a theme-based content course, and a sheltered-content course. Learners rated different aspects of their development in language, skills, and strategies-as well as motivational factors-over two semesters. Overall, learners rated the language-based course more highly in the first semester and the two content courses more highly in the second. Three conclusions were drawn: first, variation in methodology and design of the content course is such that it is difficult to generalize about generic types of content course; second, our EAP course/program might benefit from progressing asymmetrically, by starting with a more extensive language component and ending with a more extensive content component; and, third, no course was perceived by learners to provide optimum language acquisition and skills development in every domain.

\section{Content-Based Instruction and Language Learning}

Content-based language instruction is "an integrated approach to language instruction drawing topics, texts and tasks from content or subject matter classes, but focusing on the cognitive, academic language skills required to participate effectively in content instruction" (Crandall \& Tucker, 1990, p. 83). The theoretical basis for content-based learning derives from Krashen's (1981, 1982; Krashen \& Terrell, 1983) input hypothesis, which has been supported by the apparent success of immersion teaching in schools in Canada (Swain \& Lapkin, 1988).

Brinton, Snow, and Wesche (1989) identify three models of content-based instruction at secondary and tertiary levels: the theme-based model, the sheltered model, and the adjunct model. In the theme-based model, the curriculum is structured around topics relevant to the students' experience. In the sheltered model, second-language learners are segregated and taught mainstream content by subject specialists who "rough-tune" the language input to the level of the students' linguistic competence. In the adjunct model, a mainstream specialist course and a language-based course are run 
simultaneously with the same subject input and assignments (Benesch, 1988; Snow \& Brinton, 1988; Brinton et al., 1989).

We are involved in the teaching of a first-year foundation ESOL program that is part of a three-year general degree course (BA) in EFL or ELT at the Centre for English Language Teaching (CELT), now part of the Institute of Education, Stirling University, in Scotland. This foundation program is made up of three strands: one is a language-based course grounded in the communicative approach to language teaching (CLT); and two are content courses, a theme-based model (EAP) and a sheltered-content model. After the initial foundation year, in the second year of their degree program, BAEFL students go on to combine one compulsory language description program in CELT each semester with their own choice of subjects provided in other departments, one of which must be followed through to advanced level. In their second year, BAELT students take a fixed program combining courses in methodology and language description from CELT with courses in general education from other parts of the Stirling Institute of Education.

Each strand of the foundation year consists of two courses that run for two 12-week semesters and make up a full academic year. Because most students do not take up mainstream academic courses until their second year of study, the adjunct model is inapplicable in this program. Each course involves two two-hour seminars a week for 12 weeks and is taught by teachers with at least 15 years' experience and a master's degree related to TESOL.

Language-based course. The main aim of our language-based course is to develop the language competence necessary for living and studying in the United Kingdom. This course develops the four general language skills of speaking, listening, reading, and writing by looking at a variety of everyday contexts and how language is used in different media and types of text. Speaking is developed in the context of discussions, seminar skills, and presentations; listening is developed in the context of intensive and extensive listening practice using audio- and videocassettes; reading is developed in the context of tasks based on authentic everyday texts such as newspaper articles; and writing is developed in the context of descriptive and comparative essays, book and film reviews, and summaries (CELT, 1997b, 1997d). Overall, the distinctive feature of the language-based course is its explicit focus on language skills in a communicative framework.

Theme-based model. The main aim of our theme-based content course is to provide students with the academic skills necessary to study in mainstream academic courses in the Institute of Education and elsewhere in the university. The course progresses from giving prominence to skills in the first semester, to giving prominence to topics (or themes) in the second. In the first semester, students cover academic skills such as notetaking, paraphrasing, signposting, and conventions of referencing. They also look at 
topics that are sufficiently complex to require an academic approach to research and argumentation, but that we feel are relevant to their personal concerns, such as environmental and human rights issues. In the second semester, students look at topics grouped thematically into four blocks according to their most popular second-year options: sociology, business, education, and film studies (CELT, 1997a, 1997c). The distinctive feature of the theme-based course is its explicit focus on academic skills.

Sheltered-content model. The main aim of our sheltered-content course is to introduce students to aspects of British culture and society. This course consists of four British studies modules: on social issues and politics and government delivered in semester 1; and on the media and short modern fiction delivered in semester 2 (CELT, 1997e, 1997f). Course input consists of authentic academic texts and oral presentations made by the course tutors that are rough-tuned to the learners' levels of linguistic competence. Coursework comprises analytical essays written on each of the four modules. The distinctive feature of our sheltered-content model is its rough-tuned delivery of academic content.

Learners. In 1997, 22 first-year entrants took all three courses: 8 from Greece, 2 from Cyprus, 1 from Germany, 1 from France, 6 from Hong Kong, 2 from Taiwan, and 2 from Japan. The proportion of women to men was approximately $3: 1$, with ages ranging from 18 to 30 .

Context of learning. Another way of understanding the difference between the three courses in our undergraduate program is to consider "the range of contextual support" that is available for expressing and receiving meaning in the activities designed for each one. Cummins and Swain (1986) distinguish between activities that are embedded in a context; and those in which the context is reduced. Two aspects of context can be mobilized to help learners understand the meaning of the communication that is taking place. The first is the extent to which interactional, paralinguistic communication is created and maintained during activities performed by the learners:

In context-embedded communication the participants can actively negotiate meaning (i.e., by providing feedback that the message has not been understood) and the language is supported by a wide range of meaningful paralinguistic and situational clues; context-reduced communication, on the other hand, relies primarily (or at the extreme end of the continuum, exclusively) on linguistic cues to meaning and may in some cases involve suspending knowledge of the "real" world in order to interpret (or manipulate) the logic of the communication appropriately. (p. 152)

The second is the extent to which the learners have a shared knowledge of the frame of reference of activities in the course: 
In general, context-embedded communication derives from interpersonal involvement in a shared reality that obviates the need for explicit linguistic elaboration of the message. Context-reduced communication, on the other hand, derives from the fact that this shared reality cannot be assumed, and thus linguistic messages must be elaborated precisely and explicitly so that the risk of misinterpretation is minimised. (p. 152)

We can, therefore, situate the type of activities in each of our courses on a continuum (Figure 1) that reflects the extent to which nonlinguistic scaffolding and shared meanings between learners are mobilized to facilitate comprehension.

At one end of this spectrum, the tasks and activities employed on our communicative language teaching course maximize both aspects of embedded context in order for learners to understand the language input. However, the more the courses replicate the discourse of a mainstream academic content course, the less these forms of context are created and maintained in classroom activities.

\section{The Investigation}

The aim of our investigation was to check whether the combination of courses in our first-year ESOL foundation program maximizes the opportunities for language acquisition and skills development. It was intended as a small-scale piece of classroom research to enable us to reflect on the experiences of learners in the undergraduate program and possibly to feed their experiences back into subsequent program revision. This led us to ask our participants five questions in order to assess their perceptions of the effectiveness of our three different models of language instruction:

1. Does our language-based course improve learners' language skills more than our courses that have a less explicit focus on language?

2. Does our theme-based (EAP) model improve learners' study skills and awareness of academic discourse more than our courses that have a less explicit focus on study skills?

\begin{tabular}{|c|c|c|c|}
\hline $\begin{array}{l}\text { [Adjunct } \\
\text { Model] }\end{array}$ & $\begin{array}{l}\text { Sheltered } \\
\text { Content } \\
\text { Model }\end{array}$ & $\begin{array}{l}\text { Theme } \\
\text { Based } \\
\text { Model }\end{array}$ & $\begin{array}{l}\text { Language } \\
\text { Based } \\
\text { Course }\end{array}$ \\
\hline $\begin{array}{l}\text { Context } \\
\text { reduced }\end{array}$ & & & $\begin{array}{l}\text { Context } \\
\text { embedded }\end{array}$ \\
\hline
\end{tabular}


3. Is our sheltered-content model, which has a greater focus on course content, more interesting and motivating for learners than our courses that focus more on language and on skills?

4. Do learners learn more subject (or content) knowledge through our sheltered-content model?

5. Is there any change or development in what our students perceived they learned across consecutive semesters?

\section{Methods}

A questionnaire (Appendix A) was issued to first-year undergraduates $(n=22)$ at the end of their first and second semesters. A different retrospective questionnaire (Appendix $B$ ) was also issued to second- and third-year undergraduates $(n=34)$ at the end of their year of study in order to monitor how effective they found the courses now that they had gone on to study academic courses in other departments. Students responded on a six-point Likert scale $(0-5)$. The mean responses to each question were calculated across the groups $(n=22)$ for each question. These are displayed in the tables below.

\section{Results}

\section{Learners' Evaluations of Current Courses}

The different course models were evaluated by learners in each of two semesters for their perceived effectiveness in four areas: input-listening and reading; output-writing and speaking; selected learning strategies-metacognitive and cognitive (O'Malley \& Chamot, 1990); and motivational aspects of the courses as a whole, including the amount of new subject knowledge learned.

Input. Overall, learners perceived that their competences in reading and listening (Tables $1 \& 2$ ) improved more on the language-based course in the first semester and more on the two content courses in the second semester. In the first semester, learners perceived that their reading (Table 1) improved most on the language-based course in three of the four areas investigated: comprehension (understanding the language of the text); notetaking (study skills); and organization (understanding the structure of a text). In the second semester, learners perceived that taking notes from reading developed more on the theme-based model than on the other two courses, but all other aspects of reading improved more on the sheltered model. Some of the reading input on this course was derived from a half-semester module in modern UK fiction.

In terms of listening, there was a similar trend across the two semesters (Table 2). Learners perceived that three of the four areas of listening skills investigated-comprehension, organization, and monitoring-improved the 
Table 1

Learners' Perceptions of Improvements in Reading ( $n=22$ )

\begin{tabular}{lcccccc}
\hline & Language & $\begin{array}{c}\text { Semester 1 } \\
\text { Theme } \\
\text { Based }\end{array}$ & $\begin{array}{c}\text { Sheltered } \\
\text { Content }\end{array}$ & $\begin{array}{c}\text { Language } \\
\text { Based }\end{array}$ & $\begin{array}{c}\text { Semester 2 } \\
\text { Theme } \\
\text { Based }\end{array}$ & $\begin{array}{c}\text { Sheltered } \\
\text { Content }\end{array}$ \\
\hline Comprehension & 3.33 & 2.68 & 2.29 & 2.94 & 3.19 & 3.87 \\
Notetaking & 3.33 & 3.18 & 2.71 & 3.00 & 3.31 & 3.27 \\
Organization & 3.30 & 3.14 & 2.50 & 2.94 & 3.13 & 3.93 \\
Monitoring & 3.00 & 3.00 & 2.57 & 3.12 & 3.38 & 3.53 \\
\hline
\end{tabular}

most in the semester 1 language-based course. Not surprisingly, they perceived their notetaking skills improved most in the EAP course where many of the in-class activities included taking notes from an audio- or videotape. In semester 2, they perceived that the content-based courses served them better in this area, although they perceived their notetaking improved on the language-based course. The more global skills of understanding textual organization and monitoring understanding improved most on the EAP course, which made extensive use of educational videos and audiotaped lectures. They perceived their comprehension (at a linguistic level) improved most on the sheltered-content course, which contained modules in media studies and literature. Interestingly, the second semester of the languagebased course contained a large number of listening activities but little explicit teaching of notetaking strategies.

Output. With regard to the general language skills of writing and speaking, learners again reported that they improved in more discrete areas during the language-based course in semester 1 and in more areas in the content courses in semester 2. As Table 3 reveals, in semester 1, learners perceived that the language-based course best helped them to improve their writing in the areas of grammatical and textual competence on the language-based course (spelling, vocabulary, grammar, accuracy, and paraphrase). How-

Table 2

Learners' Perceptions of Improvements in Listening ( $n=22)$

\begin{tabular}{lcccccc}
\hline & Language & $\begin{array}{c}\text { Semester 1 } \\
\text { Theme } \\
\text { Based }\end{array}$ & $\begin{array}{c}\text { Sheltered } \\
\text { Based }\end{array}$ & $\begin{array}{c}\text { Language } \\
\text { Based }\end{array}$ & $\begin{array}{c}\text { Semester 2 } \\
\text { Theme } \\
\text { Based }\end{array}$ & $\begin{array}{c}\text { Sheltered } \\
\text { Content }\end{array}$ \\
\hline Comprehension & 3.33 & 2.73 & 3.07 & 3.35 & 3.44 & 3.67 \\
Notetaking & 3.00 & 3.38 & 3.08 & 3.41 & 3.00 & 3.33 \\
Organization & 3.42 & 2.82 & 3.00 & 3.06 & 3.37 & 3.33 \\
Monitoring & 3.00 & 2.82 & 2.77 & 3.06 & 3.38 & 3.20 \\
\hline
\end{tabular}


Table 3

Learners' Perceptions of Improvements in Writing ( $n=22)$

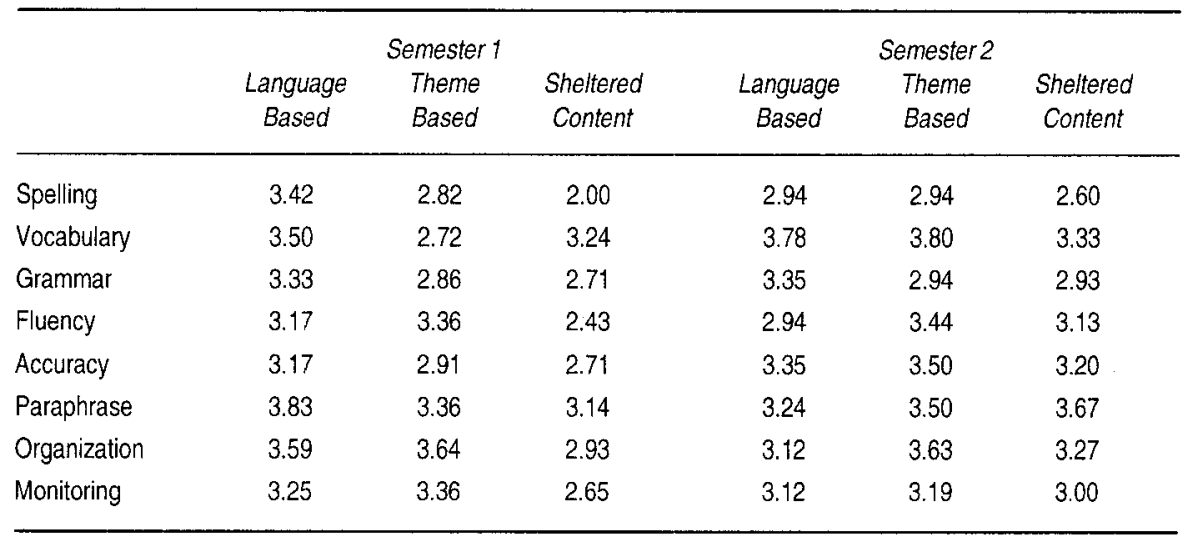

ever, they perceived that the first semester theme-based course helped them more in improving the more global areas of fluency, monitoring, and organizing their writing at a discourse level. In the second semester, learners still perceived that the language-based course helped them most with their grammar and spelling. However, when the theme-based course became organized more around topics rather than skills, learners perceived that it offered them the most improvement in all other areas-both at a linguistic and a global level-except, curiously, paraphrasing. Learners perceived that their capacity to write in their own words improved most on the media and literature modules in semester 2 . This could be because they perceived that the literature module enriched the linguistic resources that they brought to the reformulation of other texts.

In the first semester, the same patterns are maintained with respect to how our learners perceived their speaking improved across the three courses (Table 4). In semester 1, learners rated the language-based course as helping them most with all seven categories of input considered. However, in semester 2, although learners still perceived that the language-based course helped them most with their pronunciation and use of grammar, they perceived that all five other aspects of speaking improved most through the sheltered-content model. The methodology of the modular media and fiction course required a high level of discussion and oral participation from students in the seminar. However, practically no activities focused directly on the development of either composing skills or learning strategies; moreover, in keeping with many other modes of content teaching (Swain, 1988), there was a minimal level of teacher feedback on linguistic accuracy.

Learning strategies. Learners perceived that they developed their language awareness and their ability to guess the meanings of words (a cognitive 
Table 4

Learners' Perceptions of Improvements in Speaking ( $n=22)$

\begin{tabular}{lcccccc}
\hline & Language & $\begin{array}{c}\text { Semester } \\
\text { Theme } \\
\text { Based }\end{array}$ & $\begin{array}{c}\text { Sheltered } \\
\text { Based }\end{array}$ & $\begin{array}{c}\text { Language } \\
\text { Based }\end{array}$ & $\begin{array}{c}\text { Semester2 } \\
\text { Theme } \\
\text { Based }\end{array}$ & $\begin{array}{c}\text { Sheltered } \\
\text { Content }\end{array}$ \\
\hline Pronunciation & 2.83 & 2.05 & 2.00 & 3.35 & 2.25 & 3.13 \\
Vocabulary & 3.00 & 2.68 & 2.43 & 3.18 & 2.94 & 3.74 \\
Grammar & 3.00 & 2.50 & 1.58 & 3.42 & 2.44 & 2.74 \\
Fluency & 3.17 & 2.73 & 2.29 & 3.24 & 3.13 & 3.94 \\
Accuracy & 3.00 & 2.59 & 2.14 & 3.18 & 2.75 & 3.53 \\
Communication & & & & & & \\
strategies & 2.92 & 2.59 & 2.50 & 2.76 & 2.81 & 3.53 \\
Monitoring & 2.75 & 2.41 & 2.29 & 2.76 & 2.75 & 2.93 \\
\hline
\end{tabular}

strategy) most on the semester 1 language-based course (Table 5). With regard to language awareness, this remained the case in the second semester, although as the program developed, they perceived the sheltered-content course most improved their ability to guess the meaning of words. Our learners also perceived in the second semester that their ability to find source materials (a metacognitive strategy) improved most in the theme-based course, although there was not much difference between the three courses in the first semester.

Motivational factors. Learners' perceptions of the validity or authenticity of a course are crucially motivating (Breen, 1985; Taylor, 1994; Lee, 1995; MacDonald, Badger, \& White, in press). Learners were asked three questions regarding how they felt about the authenticity of each course (see Appendix A). The first question asked how relevant the course was for them. This was intended to assess whether they saw the course as relating to the experience that they brought to the program; that is, it was an assessment of the learner authenticity of the course. The second question asked whether learners saw the course as relating to their future studies. This was intended to assess

Table 5

Perceptions of Improvements in Learning Strategies ( $n=22)$

\begin{tabular}{|c|c|c|c|c|c|c|}
\hline & \multicolumn{3}{|c|}{ Semester 1} & \multicolumn{3}{|c|}{ Semester 2} \\
\hline & $\begin{array}{c}\text { Language } \\
\text { Based }\end{array}$ & $\begin{array}{l}\text { Theme } \\
\text { Based }\end{array}$ & $\begin{array}{c}\text { Sheltered } \\
\text { Content }\end{array}$ & $\begin{array}{c}\text { Language } \\
\text { Based }\end{array}$ & $\begin{array}{l}\text { Theme } \\
\text { Based }\end{array}$ & $\begin{array}{c}\text { Sheltered } \\
\text { Content }\end{array}$ \\
\hline Guess meanings & 3.50 & 2.82 & 2.14 & 3.24 & 3.00 & 3.60 \\
\hline Grammatical rules & 3.25 & 2.59 & 1.93 & 3.12 & 2.31 & 2.74 \\
\hline Find source materials & 3.33 & 3.28 & 3.29 & 2.41 & 3.25 & 3.00 \\
\hline
\end{tabular}


whether they saw the course as relating to their anticipated experience; that is, it was an assessment of the target authenticity of the course. Third, learners were also asked how much new (subject or content) knowledge they felt they learned on the course. This was intended to assess whether learners saw the course as meaningful in terms of a here-and-now learning experience; that is, it was an assessment of the classroom authenticity of the course. A fourth potentially motivating factor was taken as being the level of interest each course held for the learners. In semester 1, learners perceived that the language-based course was not only of most relevance to their prior experience and related most to their future studies, but was also the most interesting course (Table 6). Unsurprisingly, though, they perceived they learned most new subject knowledge on the sheltered-content course. By contrast, in the second semester, learners rated the sheltered-content course the highest with respect to four potentially motivating factors, perhaps because it contained the media and literature modules.

\section{Retrospective Learner Evaluations of Courses}

Second-and third-year learners were also given a questionnaire asking them to assess retrospectively across both semesters in their first year of study which of the three different courses had most improved their use of the English language and had best prepared them for their subsequent years of study. As a measure of how much subject knowledge they perceived they had learned on the three different courses, they were also asked how much each course had developed their knowledge of UK culture.

With hindsight, learners indicated (Table 7) a perception that the themebased content model had best improved not only their study skills, but also, in contrast to the aggregate view of the learners currently taking the course, their language skills across their two first-year semesters. They also, unsurprisingly, perceived that they had learned much more about UK culture from the sheltered-content model. There was no notable variation in the mean rankings between second- and third-year cohorts.

Table 6

Learners' Perceptions of Motivating Factors $(n=22)$

\begin{tabular}{|c|c|c|c|c|c|c|}
\hline & \multicolumn{3}{|c|}{ Semester 1} & \multicolumn{3}{|c|}{ Semester 2} \\
\hline & $\begin{array}{c}\text { Language } \\
\text { Based }\end{array}$ & $\begin{array}{l}\text { Theme } \\
\text { Based }\end{array}$ & $\begin{array}{c}\text { Sheitered } \\
\text { Content }\end{array}$ & $\begin{array}{l}\text { Language } \\
\text { Based }\end{array}$ & $\begin{array}{l}\text { Theme } \\
\text { Based }\end{array}$ & $\begin{array}{c}\text { Sheltered } \\
\text { Content }\end{array}$ \\
\hline Relevance & 3.50 & 3.32 & 3.21 & 2.76 & 2.81 & 4.07 \\
\hline Future studies & 3.42 & 3.09 & 2.79 & 2.88 & 2.63 & 4.07 \\
\hline New knowledge & 3.58 & 3.36 & 3.71 & 2.94 & 3.31 & 4.07 \\
\hline Interest & 3.67 & 3.14 & 3.61 & 2.94 & 3.37 & 4.67 \\
\hline
\end{tabular}


Table 7

Retrospective Learners' Evaluation of Three Courses ( $n=34$ )

\begin{tabular}{lccc}
\hline & $\begin{array}{c}\text { Language } \\
\text { Based }\end{array}$ & $\begin{array}{c}\text { Theme } \\
\text { Based }\end{array}$ & $\begin{array}{c}\text { Sheltered } \\
\text { Content }\end{array}$ \\
\hline Language & 3.00 & 3.73 & 3.30 \\
Study skills & 2.73 & 3.56 & 3.13 \\
Knowledge of culture & 2.50 & 2.82 & 3.83 \\
\hline
\end{tabular}

\section{Discussion}

The scope of this piece of research clearly restricts the generalizability of the results. This applies in particular to the small number of participants studied, but also to other factors such as the lack of gender balance in the group under investigation. However, we can go on to consider to what extent the results of our study answer the five questions posed earlier in relation to assessing our particular learners' experiences and their implications for our first-year undergraduate program.

We begin with the issue of the effectiveness of our courses insofar as they focus explicitly on language and study skills (questions 1 and 2). There appeared to be a progression in the way learners perceived the improvement in their language skills depending on whether they were in their first or second semester. In the first semester, they saw the language-based course as being most beneficial in most areas of language competence, whereas in the second semester they perceived that they improved more in aspects of both accuracy and fluency in both types of content course. With hindsight, second- and third-year students perceived that their use of the English language improved most in the theme-based content course of both semesters. Although there was greater variation in the overall trend, we can see a similar progression in the way students perceived their study skills developing across the two semesters. ${ }^{1}$ Students again generally perceived that their study skills developed most in the language-based course during the first semester, but in one of the two content courses during the second semester. Areas in the first semester where there were exceptions to this (notetaking from listening in Table 2, organization and monitoring of writing in Table 3) may have been caused by specific focusing of activities on these skills in the theme-based course. There are at least two possible reasons for this shift.

The first relates to students' expectations of different types of course. This can be seen both as a limitation and as an implication of our study. Many of our students come from cultures where it is likely that explicit grammar instruction is seen as the most effective type of language teaching. Most of our learners will have come to the program expecting the format of the language-based course to be most effective in teaching them English. How- 
ever, it may be that by the end of their second semester their expectations of the effectiveness of the different types of course had changed as they became acculturated into the teaching approach of our department. This is even more true of second- and third-year students who in some cases go on to study methodology courses in TESOL. These prior expectations of the different types of course could be dismissed as a factor skewing learners' perceptions. But they could equally well have had an effect on their learning outcomes.

The second possible reason is that the students learned more from different types of course because their competence in both language and study skills was developing. The implication of this may be that learners-especially from cultures that rely on high levels of didactic learning-respond to a high level of explicit language teaching at the beginning of their program; but as their language competence and pedagogic acculturation develop through their first year, they can be weaned off this onto less explicit, taskbased approaches.

We now consider how learners felt about motivation and the amount of subject knowledge learned (questions 3 and 4). In semester 1, all motivational factors were rated most highly for the language-based course; and in semester 2, for the sheltered-content course. But all our learners, unsurprisingly, perceived that they learned most new subject knowledge in the sheltered-content course regardless of semester or year group. Two factors again may have influenced the motivation of the learners. The first was the issue of their prior expectations mentioned above; and the second was the progression in the modular content of the sheltered-content course. In the first semester, the course modules looked at social issues and modern British history and politics, topics that students regularly complained about in class and on their in-house course evaluations. In the second semester, the course focused on media studies and short modern fiction, which the learners received enthusiastically.

Finally, in terms of consistency of response (question 5), learners only appeared to rate the least problematic domain-namely, that of the amount of subject or content knowledge learned-consistently across two semesters. But although the domains of language acquisition and skills development were not consistent across the two semesters, there appeared to be some coherence in the progression in ratings from the language-based course in semester 1 to the two types of content course in semester 2 .

However, we should be wary of reading too much into this coherence. There is an issue here regarding the consistency of the design and delivery of the three different types of course across the two semesters. Both languagebased courses and the different models of content-based course can vary widely depending on the two key design features of methodology and topic orientation. It has been suggested that this variation, particularly with regard 
to methodology of content-based courses, can involve a deficiency in linguistic input for the learner (Swain, 1988). Precisely because typical content courses are entirely meaning-oriented, they possibly provide learners not only with "inconsistent and possibly random information about their target language use," but also with "functionally restricted language input" (pp. 72-77). Clearly, however, the degree of inconsistency and restriction on any model of content course varies greatly according to the approach of individual teachers and the approach taken by different course designers. The variation in skills and topic orientations that has also been observed in the theme-based and sheltered-content models across the two semesters actually points to a difficulty in describing them as homogenous models. It might, therefore, be more valid to evaluate the efficacy of a specific course design in a particular learning situation with regard to its provision of the particular learners' needs than to work in generalized definitions of course model such as those derived from Brinton et al. (1989).

With this caveat, however, we could still allow that the coherence of progression across semesters possibly reflects the progress built into the program. That is to say, in the first semester, it is possible that our learners rated domains of the language-based course higher precisely because they needed this scaffolding in order to cope with the two content courses of the program. The practical implication this might have for our program design is that our learners would possibly benefit from having a more extensive language-focused component at the beginning of a foundation ESOL program that might gradually be skewed toward a more extensive content-based component by the end of the program.

Overall, our learners' responses appear to support our maintaining some mix of language-based, theme-based, and sheltered-content courses on our ESOL foundation program, inasmuch as no course-and especially the sheltered-content course, as implied by our reading of the input hypothesiswas perceived by learners to offer them a full range of language acquisition and skills development. In particular, learners perceived that the shelteredcontent course appeared to offer them less in specific domains relating to the accuracy of their linguistic output. In this respect, our learners' experience would appear to militate against (although it can in no way disprove) the implications of the input hypothesis (Krashen, 1981, 1982; Krashen \& Terrell, 1983) that learners can learn every aspect of language solely from input that is meaningful and roughly tuned to their level, the practical realization of which would be a program based exclusively on variations of the sheltered model of a content course. With regard to language acquisition, even in the second semester where learners perceived that the content courses generally developed most of the domains we looked at, they still viewed the languagebased course as helping them most in accuracy of linguistic output (especially pronunciation and both spoken and written grammar). A similar situation 
appears to be the case with regard to skills development. In the second semester, learners perceived that the sheltered model most helped their writing and - paradoxically - speaking strategies (monitoring and discourse awareness); however, they still perceived that the more focused theme-based EAP course helped them most with their listening and, crucially, writing strategies (discourse awareness and monitoring).

\title{
Conclusion and Future Research
}

Learners' general perception that the language-based course helped them in a wider range of language acquisition and skills development in semester 1 than semester 2, whereas the content courses were more helpful in semester 2 than in semester 1 , leads us to reflect whether our program might benefit by starting with a more extensive language component and ending with a more extensive content component. Our further research would clearly benefit by using some measures of proficiency to complement introspective data from our learners. However, it is hard to isolate different factors when learners are simultaneously engaged in three different types of course. A preferred situation for investigating the relationship between course design and language/skills proficiency would be where a homogeneous group of learners could be split into three different cohorts and each cohort being assigned to one different type of course.

\begin{abstract}
Note
${ }^{1}$ We considered study skills in two areas: those relating to the four general language skills (notetaking, discourse organization, communication strategies, and monitoring in Tables 1-4); and cognitive/metacognitive learning strategies (guessing meaning from context, working out grammatical rules and finding source materials in Table 5).
\end{abstract}

\section{The Authors}

The authors lecture at the Centre for English Language Teaching (CELT), at the University of Stirling, UK. Richard Badger has previously taught in Nigeria, Malaysia, Algeria, and the UK; Malcolm MacDonald has previously taught in the Seychelles, Kuwait, Singapore, Malaysia, and the UK; Goodith White has previously taught in Italy, Finland, Singapore, Portugal, Eire, and the UK. She is currently pursuing doctoral research in sociolinguistics with Trinity College, Dublin, and has recently published a book on listening for OUP.

\section{References}

Benesch, S. (Ed.). (1988). Ending remediation: Linking ESL and content in higher education. Washington, DC: TESOL.

Breen, M.P. (1985). Authenticity in the language classroom. Applied Linguistics, 6(1), 60-70.

Brinton, D.M., Snow, M.A., \& Wesche, M.B. (1989). Content-based second language instruction. New York: Newbury House.

Crandall, J., \& Tucker, G.R. (1990). Content-based instruction in second and foreign languages. In S. Anivan (Ed.), Language teaching methodology for the nineties (pp. 83-96). Singapore: RELC. 
Centre for English Language Teaching (CELT). (1997a). EL01: English for academic purposes-Autumn semester. Unpublished course description. University of Stirling, UK: Author.

CELT. (1997b). EL02; General English-Autumn semester. Unpublished course description. University of Stirling, UK: Author.

CELT. (1997c). EL03: English for academic purposes--Spring Semester. Unpublished course description. University of Stirling, UK: Author.

CELT. (1997d). EL04: General English-Spring semester. Unpublished course description. University of Stirling, UK: Author.

CELT. (1997e). EL11: 20th century Britain-British society 1945 to 1997-Autumn semester. Unpublished course description. University of Stirling, UK: Author.

CELT. (1997f). EL11: 20th century Britain-media and modern fiction-Spring semester. Unpublished course description. University of Stirling, UK: Author.

Cummins, J., \& Swain, M. (1986). Bilingualism in education. London: Longman.

Krashen, S. (1981). Second language acquisition and second language learning. Oxford: Pergamon.

Krashen, S. (1982). Principles and practice in second language acquisition. Oxford: Pergamon.

Krashen, S., \& Terrell, T.D. (1983). The natural approach: Language acquisition in the classroom. Oxford:Pergamon.

Lee, W.Y. (1995). Authenticity revisited. ELT Journal, 49, 323-328.

MacDonald M.N., Badger, R., \& White, G. (in press). The real thing? Authenticity and academic listening. ESP Journal.

O'Malley, J.M., \& Chamot, A.U. (1990). Learning strategies in second language acquisition. Cambridge: Cambridge University Press.

Snow, M.A., \& Brinton, D.M. (1988). Content-based language instruction: Investigating the effectiveness of the adjunct model. TESOL Quarterly, 22, 553-574.

Swain, M. (1988). Manipulating and complementing content teaching to maximize second language learning. TESL Canada Journal, 6(1), 68-83.

Swain, M., \& Lapkin, S. (1988). Canadian immersion and adult second language teaching: What's the connection? Paper presented at the first OSU/MLJ Conference on Research Perspective in Adult Language Learning and Acquisition, Ohio State University.

Taylor, D. (1994). Inauthentic authenticity or authentic inauthenticity? TESL-EJ, 1(2), 1-11. 


\section{Appendix A \\ First-Year Undergraduate Language Skills Questionnaire}

This is one of a series of questionnaires we are asking you to fill in. Its purpose is to find out how much the different courses on the first-year program improve your language skills. Please answer the questions that follow. All responses will be treated as strictly anonymous.

Nationality

$\begin{array}{lllll}\text { Age } & \text { under } 20 & 20-25 & 25-30 & \text { over } 30 \\ \text { Sex } & \text { M } & & \text { F } & \end{array}$

This course is EL01/03 EL02/04 EL11/12

\section{Speaking}

This course helped you to:

- speak with better pronunciation

not at all

a lot

- use a wider range of words when you speak

012345

012345

- speak with better grammar

012345

- speak more easily

012345

- speak more accurately

012345

- speak at the right moment

012345

- check what you have spoken

012345

\section{Writing}

This course helped you to:

- write with better spelling

- use a wider range of words when you write

- write with better grammar

- write more easily

- write more accurately

- write what you have read in your own words

- organize your writing

- check your writing

not at all

a lot

012345

012345

012345

012345

012345

012345

012345

012345

\section{Listening}

This course helped you to:

not at all

a lot

- understand spoken language

012345

- take notes

012345

012345

- understand the organization of what was said

012345

- check whether you have understood what you heard

\section{Reading}

not at all

a lot

This course helped you to:

- understand written language

012345

- take notes

012345

- understand the organization of the reading

012345

- check whether you have understood what you read

\section{Study skills}

012345

This course helped you to:

not at all

a lot

- guess the meanings of words in a text

- work out grammatical rules for using English

- find the right source materials for studying, essay writing, etc. 012345 
- How much new knowledge did you learn?

- How relevant was this course to your future students?

- How much did this course relate to your experience?

- How interesting was this course?

\section{Appendix B: Second- and Third-Year Retrospective Questionnaire}

We are trying to find out how useful you think the first-year courses of your BAELT/BAEFL program have been for you now that you are in your second and third years. Please answer the questions that follow. All responses will be treated in strict confidence.

\begin{tabular}{lllll} 
Nationality & \multicolumn{2}{c}{} & \\
Sex & M & F & $25-30$ & over 30 \\
Degree & under 20 & $20-25$ & & \\
Year & BAEFL & BAELT & &
\end{tabular}

If BAEFL, what non-CELT courses are you studying?

Year 2

Year 3

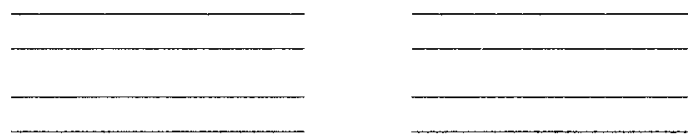

Study skills: how much have the different first-year courses prepared you for your studies in years 2 (and 3$)$ ?

EL01/EL03 English for Academic Purposes

not at all a lot

EL02/EL04 General English

012345

EL11/EL12 Society, Politics, Media, Literature

012345

012345

Language: how much have the different first-year courses improved your use of the English Language?

EL01/EL03 English for Academic Purposes

not at all

English for Acaral English

EL02/EL04

Society, Politics, Media, Literature

012345

012345

Culture: How much have the different first-year courses developed your knowledge of English culture?

EL01/EL03 English for Academic Purposes

not at all

012345

EL02/EL04

General English

012345

EL11/EL12 Society, Politics, Media, Literature

012345 